\title{
NOTE
}

\section{Amphiphatic Piperazine, Pyrazine, and Pyridine Derivaties as the Thermal Latency for Epoxy-Phenolic Resins}

\author{
By Kun-Lung CHEN, ${ }^{2,4}$ Hui-Chang LIN, ${ }^{1}$ Chun-Sheng HUANG, ${ }^{3}$ \\ Yun-Hwei SHEN, ${ }^{2}$ Jiann-Jyh HUANG, ${ }^{5}$ and Fung Fuh WONG ${ }^{1, *}$
}

KEY WORDS: Amphiphatic Catalysts / Thermal Latent Catalysts / Epoxy-Phenolic Resins / Pyrazine / Pyrindine / Piperazine /

Biphenyl type epoxy resins are thermosetting polymers widely used in the electronics industry as molding and sealing material for electronic packaging. ${ }^{1-6}$ Although the biphenyl type epoxy resins are of great advantage as highly reliable electronic molding compounds (EMC) with good adhesion and high toughness, and used as high filter loadings, their epoxy resin system has low storage stability at room temperature. As a result, latent catalysts were developed to improve the pot life at room temperature for biphenyl type epoxy resins. ${ }^{7-10}$

Latent catalysts in an epoxy resin system can be classified into two groups: thermal ${ }^{10}$ and cationic latent catalyst. ${ }^{9}$ Most of cationic latent catalysts including piperazine, ${ }^{11}$ pyrazine, ${ }^{12-15}$ and pyridine ${ }^{16-19}$ as the core were published in recent year, in which the reactivity of cationic latent catalysts were enhanced by the nucleophilicity of the couterion $\left(\mathrm{BF}_{4}{ }^{-}, \mathrm{PF}_{6}{ }^{-}, \mathrm{AsF}_{6}{ }^{-}\right.$ and $\left.\mathrm{SbF}_{6}{ }^{-}\right){ }^{20}$ However, the acidic species formed $\left(\mathrm{HBF}_{4}\right.$, $\mathrm{HPF}_{6}, \mathrm{HAsF}_{6}$ and $\mathrm{HSbF}_{6}$ ) would be released in the course of the curing polymerization to damage the electronic products. ${ }^{5}$

Amino acids are amphipathic in nature. Each molecule consists of an amino and carboxylic acid groups on $\alpha$ or other position in the same molecular. Pyrazine, pyridine, and piperazine compounds 2-7 also contained the basic and acidic functional groups in the same molecules. Herein, we reported use of amphiphatic pyrazine, pyridine, and piperazine derivative compounds 2-7 as the thermal latent amphipathic catalysts, with a structural feature containing an acidic carboxylic acid, for the polymerization of diglycidyl ether of bisphenol A (DGEBA). The nucleophilicity of amphiphatic pyrazine, pyridine, and piperazine catalysts 2-7 were deactivated, making them unable to attack the oxirane of the polymer at room temperature. At elevated temperature (100$175^{\circ} \mathrm{C}$ ), the ring-opening reaction of epoxy resin (DGEBA) could be initiated by acidic electrophilic protonation ${ }^{21}$ (compound 2-5) or attacked with the nucleophilic part ${ }^{22}$ of the catalyst (6 and 7) to underwent propagation and polymerization. The new catalysts (2-7) showed high conversions, and might suitable for being use as thermal latent catalysts.

\section{EXPERIMENTAL}

\section{Materials}

Commercial available starting materials were used as purchased. Diglycidylether of bisphenol A (DGEBA, NPEK$114 \mathrm{M})$ was purchased form Nan Ya Plastics Co. 2-Cyanopyridine, $N$-(2-hydroxyethyl)piperazine, methyl pyrazine-2-carboxylate, piperazine-2-carboxylic acid (6), 2-pyrazinecarboxylic acid (2), and 2,3-pyrazinedicarboxylic acid (3) were purchased from Sigma-Aldrich Chemical Co. 3-Aminopyrazine-2-carboxylic acid (4), ${ }^{23}$ picolinic acid (5), ${ }^{24}$ and 3 piperazin-1-yl-propionic acid (7) ${ }^{25-27}$ were prepared by following the literature procedure. Their spectroscopic data were shown in the supporting information.

\section{Differential Thermometry Analysis (TG/DTA)}

All scanning TG/DTA studies of were performed with Perkin Elemer Instruments Pyris Diamond at heating rate of $10{ }^{\circ} \mathrm{C} /$ min under $\mathrm{N}_{2}$. High purity indium and zinc were used to calibrate the calorimeter. TG/DTA studies for the cure of DGEBA with the each catalyst (2-7) at a concentration of 5, 10,15 , and $20 \% \mathrm{w} / \mathrm{w}$ are performed from $30-300{ }^{\circ} \mathrm{C}$ at heating rate of $10^{\circ} \mathrm{C} / \mathrm{min}$ under $\mathrm{N}_{2}$.

\section{Glass Transition Temperature $\left(T_{\mathrm{g}}\right)$ Measurement}

The glass transition temperature $\left(T_{\mathrm{g}}\right)$ studies are performed by using a dynamic differential scanning calorimeter (DSC, Shimadzu Instruments DSC-60), which is calibrated with indium. The samples were placed in aluminum sealed pans and were performed under a flow $(30 \mathrm{~mL} / \mathrm{min})$ of dry $\mathrm{N}_{2}$. Temperature scans were performed from $30-300{ }^{\circ} \mathrm{C}$ at heating rate of $10^{\circ} \mathrm{C} / \mathrm{min}$. The amount of sample was limited to $12-$ $15 \mathrm{mg}$ to minimize the experimental errors. The glass transition temperature $\left(T_{\mathrm{g}}\right)$ of the cure of DGEBA (DGEBA, NPEK$114 \mathrm{M}, 188-199 \mathrm{~g}$ /equiv) with the catalyst $2-7$ at a concentration of $10 \mathrm{wt} \%$ are measured and determined by a second

\footnotetext{
${ }^{1}$ Graduate Institute of Pharmaceutical Chemistry, China Medical University, No. 91 Hsueh-Shih Rd., Taichung, Taiwan 40402, R.O.C.

${ }^{2}$ Department of Resources Engineering, National Cheng Kung University, No. 1, Ta Hsueh Rd., Tainan, Taiwan 70101, R.O.C.

${ }^{3}$ Department of Chemistry, National Cheng Kung University, No. 1, Ta Hsueh Rd., Tainan, Taiwan 70101, R.O.C.

${ }^{4}$ Sustainable Environment Research Center, National Cheng Kung University, No. 500, Sec. 3, An-ming Rd., Tainan City, Taiwan 709, R.O.C.

${ }^{5}$ Development Center for Biotechnology, No. 101, Lane 169, Kangning St., Xizhi City, Taipei County, Taiwan 221, R.O.C.

*To whom correspondence should be addressed (Tel: +886 422053366 ext. 5603, Fax: +886 422078083 , E-mail: wongfungfuh@yahoo.com.tw).
} 
<smiles>OCCN1CCNCC1</smiles><smiles>N#CCCN1CCNCC1</smiles>

10

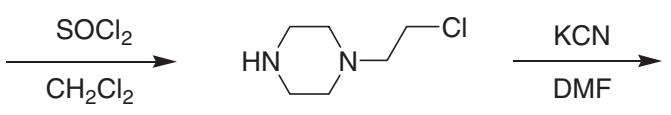

9

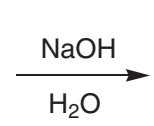

$\mathrm{H}_{2} \mathrm{O}$<smiles>O=C(O)CCN1CCNCC1</smiles>

Scheme 1.

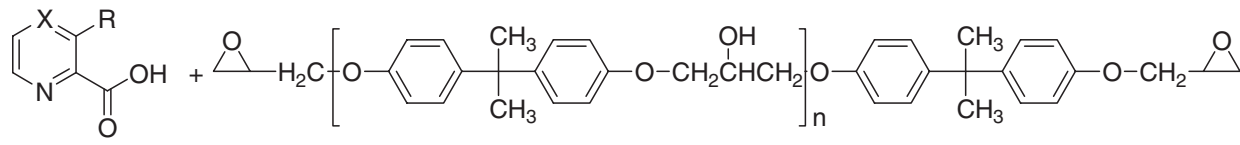

Catalysts 2-5

diglycidyl ether of bisphenol A (DGEBA)

$\mathrm{X}=\mathrm{C}, \mathrm{N}$

$\mathrm{R}=\mathrm{COOH}, \mathrm{NH}_{2}$
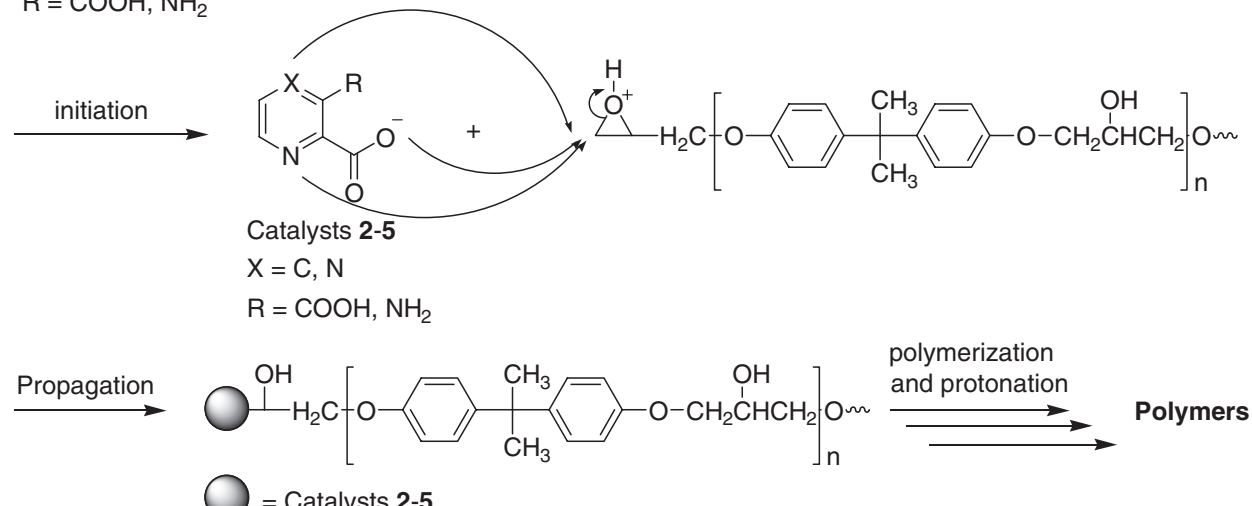

Scheme 2. Proposed mechanism of adduct formation for curing diglycidylether of bisphenol A, (DGEBA, NPEK-114M) with amphiphatic pyrazine and pyridine compounds 2-5.

run; the thermogram presents no residual heat. The epoxy (DGEBA) with BHP (1, $N$-benzylpyrazinium hexafluoroantimonate) was also done for comparison purpose.

\section{RESULTS AND DISCUSSION}

\section{Synthesis}

2-Pyrazinecarboxylic acid (2) and picolinic acid (5) were prepared by reported hydrolysis procedure from 2-cyanopyridine $^{23}$ and methyl pyrazine-2-carboxylate. ${ }^{24}$ The synthetic route of the generation of 3-piperazin-1-yl-propionic acid (7) was shown in Scheme 2. ${ }^{25-27} \mathrm{~N}$-(2-Hydroxyethyl)piperazine (8) was efficiently transformed into the corresponding 1-(2chloroethyl)piperazine (9) in 56\% yield by using thionyl chloride in $\mathrm{CH}_{2} \mathrm{Cl}_{2}$ solution in ice-bath (see Scheme 1). ${ }^{25} 1$-(2Chloroethyl)piperazine (9) was treated with $\mathrm{KCN}$ in $\mathrm{N}, \mathrm{N}$ dimethylformamide (DMF) solution at reflux, the corresponding product 10 was obtained in $47 \%$ yield. $^{26} 3$-(Piperazin-1yl)propanenitrile (10) was hydrolyzed with aqueous $\mathrm{NaOH}$ solution at reflux for $18 \mathrm{~h}$ to give the corresponding 3piperazin-1-yl-propionic acid (7) as white solids in $43 \%$ yield. $^{27}$
Measurement of the pH Value of Catalysts 2-7 in Water and the Curing Mechanism Study

Since the polymerization of DGEBA were reported to be initiated by the protonation of the oxirane followed by ring opening by the nucleophiles from the catalysts (see Scheme 2$),{ }^{28-32}$ the $\mathrm{pH}$ value of the catalyst would contribute to the efficiency of the polymerization. In aqueous solution, the amphiphatic pyrazine and pyridine compounds 2-5 were presented as moderate to strong acid and the $\mathrm{pH}$ values ranged from 1.11 to 3.37 (the blank test was performed in water and the $\mathrm{pH}$ is 6.40): 2-pyrazinecarboxylic acid (2, 1.98), 2,3pyrazinedicarboxylic acid (3, 1.11), 3-aminopyrazine-2-carboxylic acid $(\mathbf{4}, 2.74)$, and picolinic acid $(\mathbf{5}, 3.37)$. As a result, we proposed an initiate mechanism of polymerization would be initiated by the protonation of the acid species in these cases 2-5. ${ }^{21,33}$ The propagation and polymerization of epoxy were then performed by the relative stronger nucleophiles including the nitrogen or oxygen anion moieties in amphiphatic pyrazine and pyridine compounds $\mathbf{2}-\mathbf{5}$ at a moderately elevated temperature (100-175 ${ }^{\circ} \mathrm{C}$, see Scheme 2$)$.

To investigate the relatively acidcity/basicity of piperazine, pyrazine, and pyridine, we found the reported $\mathrm{p} K$ a values from 
literatures were piperazine $(\mathrm{p} K \mathrm{a}=9.73$ and 5.33) $>$ pyridine $(\mathrm{p} K \mathrm{a}=5.23)>$ pyrazine $(\mathrm{p} K \mathrm{a}=0.65) .{ }^{34}$ The $\mathrm{pH}$ data was consistence with the literature $\mathrm{p} K$ a tendency. For example, the $\mathrm{pH}$ values from experiment indicated piperazine-2-carboxylic acid $(\mathbf{6}, 10.5)>$ picolinic acid $(5,3.37)>2$-pyrazinecarboxylic acid $(2,1.98)$.

The amhiphatic piperazine catalysts 6 and 7, which contained carboxylic acid in the side chain, were with reduced nucleophilicity by forming the intra- or intermolecular acidbase neutralization. Their $\mathrm{pH}$ values were presented in 10.5 and 7.01 , respectively. Catalyst 6 was a base $(\mathrm{pH}=10.5)$ and the basicity of compound 7 was reduced for the $N$-substituting group $(\mathrm{pH}=7.01)$. Many of mechanisms were proposed for the nucleophilic catalysts (e.g. imidazole derivatives) $)^{28-32}$ and the initiation step of amhiphatic piperazine catalysts $\mathbf{6}$ and $\mathbf{7}$ was considered to directly attack the oxirane of DGEBA by the nucleophilic moiety of the catalysts at elevated temperatures.

\section{Measurement of Pot-Life ${ }^{35}$}

Sample Preparation. The catalyst level was set to $2 \% \mathrm{w} / \mathrm{w}$ to DGEBA. The viscosity and epoxide equivalent weight of DGEBA was 2100-2500 cp and 188-199 g/equiv, respectively. The samples were mixed by use of a high shear blender and degassed in vacuum oven. All samples were stored in glass vials at room temperature between viscosity measurements. The glass vials were rotated by a rotator at $\sim 10 \mathrm{rpm}$ all the time to keep the filler from settling.

Measurement of Viscosity. The viscosities of the samples were measured periodically for $600 \mathrm{~h}$ by use of a viscometer (Brook Field Instruments, model DV-II+) with parallel plate geometry and spindle (model SC4-21). The gap was set to $250 \mu$ and the test was performed at $25^{\circ} \mathrm{C}$. The test method is listed as follows:

1) Pre-shear at $10 \mathrm{~S}^{-1}$ for $30 \mathrm{~s}$

2) Stepped ramp of shear rate at $0.1-20 \mathrm{~S}^{-1}$ by 25 points, with tolerance $\leq 5 \%$ (up curve);

3) Stepped ramp of shear rate from 20 to $0.1 \mathrm{~S}^{-1}$ by 25 points, with tolerance no $\leq 5 \%$ (down curve).

4) The viscosity for each sample was calculated from the down curve.

Figure 1 illustrated the viscosity-shear rate relationship of DGEBA containing $2 \mathrm{wt} \%$ of catalyst 1-7 at room temperature. The viscosity of DGEBA treated with 2,3-pyrazinedicarboxylic acid (3) and picolinic acid (5) increased slightly from $\sim 2,000 \mathrm{cp}$ to $\sim 6,700 \mathrm{cp}$ in $600 \mathrm{~h}$, indicating that compound $\mathbf{3}$ and $\mathbf{5}$ exhibited slightly poor latency properties at room temperature (see Figure 1). For DGEBA treated with others amphiphatic compounds 2, 4, 6, and 7, however, the viscosity of DGEBA retained almost constant at $\sim 2,200 \mathrm{cp}$. These results indicated that the acidic amphiphatic pyrazine ( 2 and 4) and mild basic or basic amphiphatic piperazine catalysts (6 and 7) demonstrated similar latency properties to BHP (1) at room temperature. ${ }^{36}$

\section{The Cure Activation Energy $\left(E_{\mathrm{a}}\right)$}

The cure behaviors of DGEBA resin with catalysts 2-7 (2\%

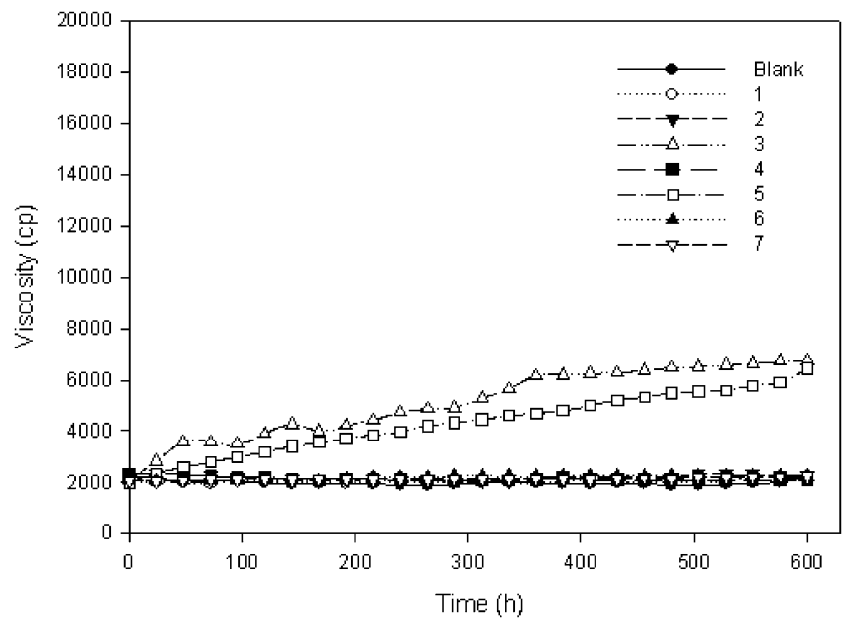

Figure 1. Diagram of the viscosity of DGEBA treated with catalyst 1-7 against storage time at $10 \mathrm{~S}^{-1}$ shear rate (N/C: DGEBA alone).

w/w) were studied with TG/DTA in the dynamic scanning mode at different heating rates. The cure activation energy $\left(E_{\mathrm{a}}\right)$ of the overall process was determined by the Kissinger method (equation 1) $)^{37,38}$ and Arrhenius method (equation 2): ${ }^{39}$

$$
\ln \left[\frac{\varphi}{T_{\mathrm{m}}^{2}}\right]=-\frac{E_{\mathrm{a}}}{R T_{\mathrm{m}}}+\ln \left[\frac{A R}{E_{\mathrm{a}}}\right]
$$

Where, $\varphi$ is the heating rate; $T_{\mathrm{m}}$ is the temperature of the maximum exothermic peak; $A$ is the pre-exponential factor; and $R$ is the gas constant $(8.314 \mathrm{~J} / \mathrm{g} \cdot \mathrm{mole} \cdot \mathrm{K})$.

$$
-\ln \left[\frac{\phi}{T_{\mathrm{p}}^{2}}\right]=\frac{E_{\mathrm{a}}}{R T_{\mathrm{p}}}-\ln \left[\frac{A R}{E_{\mathrm{a}}}\right]
$$

Where, $\varphi$ is the heating rate; $T_{\mathrm{p}}$, is peak maximum exothermic temperature; $A$ is frequency (pre-exponential) factor; and $R$ is the gas constant $(8.314 \mathrm{~J} / \mathrm{g} \cdot \mathrm{mole} \cdot \mathrm{K})$.

$E_{\mathrm{a}}$ can be obtained from the slope from the graph of $\ln \left(\varphi / T_{\mathrm{m}}{ }^{2}\right)$ versus $\left(1 / T_{\mathrm{m}}\right)$ on the basis of the equation $(1)^{37,38}$ or $\ln \left(\varphi / T_{\mathrm{P}}^{2}\right)$ versus $\left(1 / T_{\mathrm{P}}\right)^{39}$ on the basis of the equation (2). The parameter and experiment for curing DGEBA by catalyst 2-7 from TG/DTA were obtained and plotted in accordance with equation (1) and equation (2). The activation energy $E_{\mathrm{a}}$ for each process were: $1(69.26 \mathrm{~kJ} / \mathrm{mol}), 2(68.84 \mathrm{~kJ} / \mathrm{mol}), 3$ $(66.76 \mathrm{~kJ} / \mathrm{mol}), 4(76.90 \mathrm{~kJ} / \mathrm{mol}), \mathbf{5}(67.17 \mathrm{~kJ} / \mathrm{mol}), 6(84.89$ $\mathrm{kJ} / \mathrm{mol})$, and $7(74.16 \mathrm{~kJ} / \mathrm{mol})$.

We found the $E_{\mathrm{a}}$ values for DGEBA with catalyst 1-7 were in the range of $66.76-84.89 \mathrm{~kJ} / \mathrm{mol}$. The $E_{\mathrm{a}}$ values, which reflected the relative controlled polymerization, were in the order of $\mathbf{6}(84.89 \mathrm{~kJ} / \mathrm{mol})>\mathbf{4}(76.90 \mathrm{~kJ} / \mathrm{mol})>\mathbf{7}(74.16 \mathrm{~kJ} /$ $\mathrm{mol})>\boldsymbol{1}(69.26 \mathrm{~kJ} / \mathrm{mol})>\mathbf{2}(68.84 \mathrm{~kJ} / \mathrm{mol})>\mathbf{5}(67.17 \mathrm{~kJ} /$ $\mathrm{mol})>\boldsymbol{3}(66.76 \mathrm{~kJ} / \mathrm{mol})$. Their tendency is consistent with the viscosity measurements.

\section{Differential Thermometry Analysis (TG/DTA) ${ }^{40}$}

Results from TG/DTA analysis for the curing of DGEBA by use of catalysts 2-7 at four concentrations were summarized in Table I, in which showed the exotherm onset, exotherm peak, 
Table I. The exotherm onset, main peak, and total heat of DGEBA with catalysts 2-7 at a concentration of $5,10,15$, and $20 \mathrm{wt} \%$

\begin{tabular}{|c|c|c|c|c|}
\hline Catalyst & $\begin{array}{c}\text { Concentration } \\
\text { (wt \%) }\end{array}$ & $\begin{array}{c}\text { Exotherm onset } \\
\left({ }^{\circ} \mathrm{C}\right)\end{array}$ & $\begin{array}{c}\text { Exotherm peak } \\
\left({ }^{\circ} \mathrm{C}\right)\end{array}$ & $\begin{array}{c}\text { Total heat } \\
(\mathrm{J} / \mathrm{g})\end{array}$ \\
\hline \multirow{4}{*}{2} & 5 & 134 & 150 & 42 \\
\hline & 10 & 131 & 149 & 51 \\
\hline & 15 & 128 & 148 & 141 \\
\hline & 20 & 120 & 146 & 201 \\
\hline \multirow{4}{*}{3} & 5 & 117 & 137 & 94 \\
\hline & 10 & 115 & 136 & 159 \\
\hline & 15 & 113 & 135 & 174 \\
\hline & 20 & 110 & 132 & 195 \\
\hline \multirow{4}{*}{4} & 5 & 143 & 165 & 43 \\
\hline & 10 & 141 & 159 & 50 \\
\hline & 15 & 140 & 158 & 73 \\
\hline & 20 & 138 & 156 & 94 \\
\hline \multirow{4}{*}{5} & 5 & 108 & 123 & 86 \\
\hline & 10 & 106 & 121 & 161 \\
\hline & 15 & 103 & 118 & 296 \\
\hline & 20 & 100 & 116 & 470 \\
\hline \multirow{4}{*}{6} & 5 & 149 & 200 & 78 \\
\hline & 10 & 145 & 199 & 158 \\
\hline & 15 & 143 & 185 & 349 \\
\hline & 20 & 140 & 182 & 428 \\
\hline \multirow{4}{*}{7} & 5 & 135 & 161 & 94 \\
\hline & 10 & 132 & 160 & 176 \\
\hline & 15 & 129 & 158 & 181 \\
\hline & 20 & 123 & 148 & 185 \\
\hline
\end{tabular}

a The heating rate was $10^{\circ} \mathrm{C} / \mathrm{min}$.

and total heat for the polymerization. We found that the curing of DGEBA by the catalysts 2-7 showed one main exotherm peak varying with different catalyst concentration in TG/DTA and the peaks shifted towards lower temperatures when catalysts 2-7 increased (molding study see the Figure 2). That might be due to the enhancement of the reaction rate by more catalysts. $^{32}$ Total heat output revealed that all the polymerizations were exothermic, and that for the curing by amphiphatic piperazine, pyrazine, and pyridine compounds (2-7, 5-20 wt $\%$ ) were $42-470 \mathrm{~J} / \mathrm{g}$. Because 3-aminopyrazine-2-carboxylic acid 4 was an amino-acid zwitterion compound, the nucleophilicity was deactivated to provide the lower reactivity and total heats (43-94 J/g, 5-20 wt \%, see Table I). For strong acidic amphiphatic pyrazine catalysts $\mathbf{2}-\mathbf{3}$ or basic amphiphatic piperazine catalysts $6-7$, whcih possessed the strong reactivity for protonation or the relative stronger nucleophilicity from the nitrogen or oxygen anion moieties, the higher exothermic heats were generated $(42-470 \mathrm{~J} / \mathrm{g}, 5-20 \mathrm{wt} \%$, see Table I). The total heat output is important to evaluate the feasibility for the curing system, for too little total heat output indicates that no polymerization take place. However, too high total heat output revealed that the reaction may not be scaled up to industrial capacity with a satisfactory safety level. ${ }^{37}$

\section{Measurement of Glass Transition Temperature $\left(T_{\mathrm{g}}\right)$ and Conversion}

The glass transition temperature $\left(T_{\mathrm{g}}\right)$ is an important single parameters to determine the applications and properties of polymer materials. ${ }^{41}$ The $T_{\mathrm{g}}$ values of DGEBA cured with

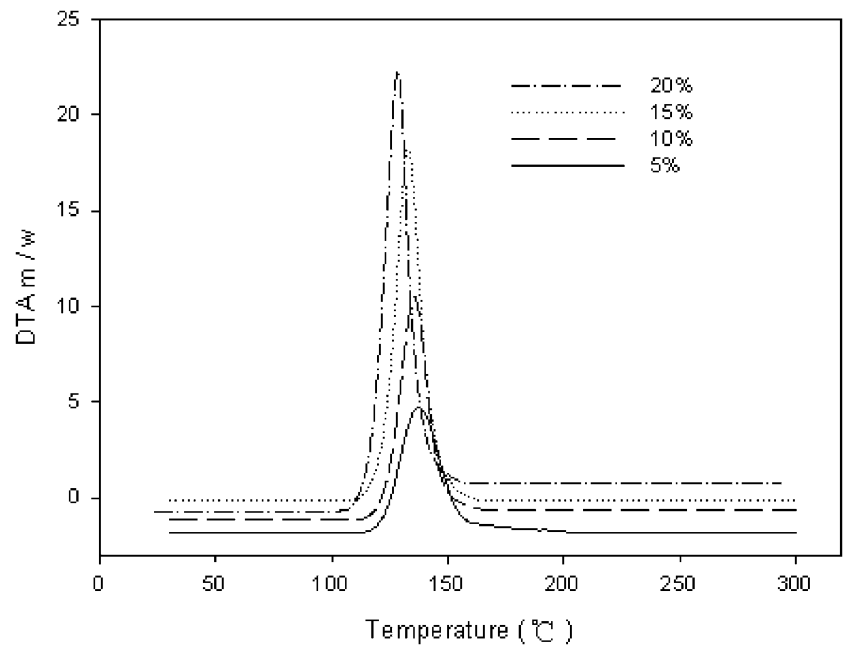

Figure 2. Scanning TG/DTA of the cure of DGEBA at $10^{\circ} \mathrm{C} / \mathrm{min}$ with 2,3 pyrazinedicarboxylic acid (3, 5-20 wt \%).

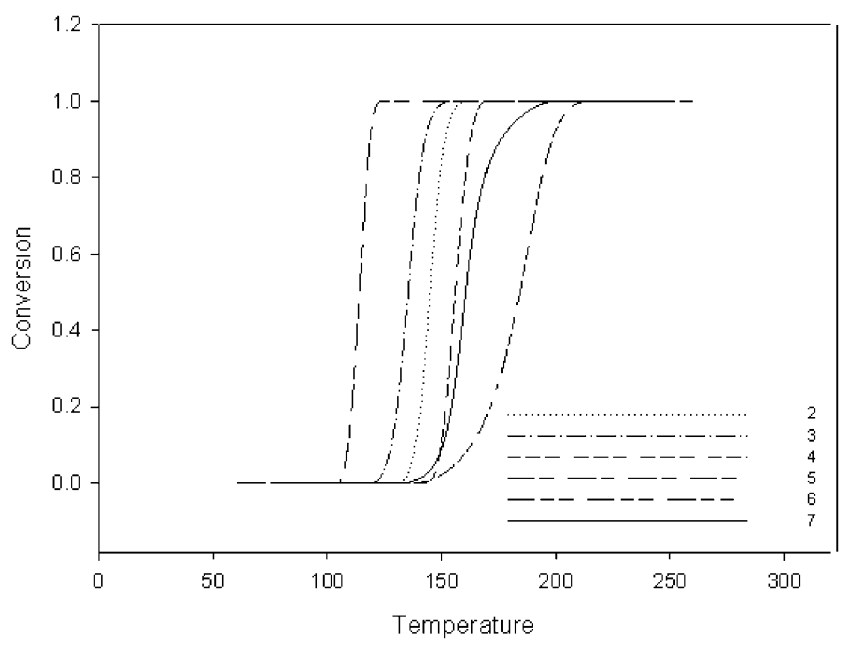

Figure 3. Conversion curves of DGEBA cured by each catalyst 2-7 as a function of the curing temperature.

catalyst depend on the amount and property of the catalysts, ${ }^{42}$ the epoxide equivalent weight of DGEBA, and the blending agents $^{41}$ (i.e., hardener, and filter). For DGEBA cured with catalysts 2-7, the $T_{\mathrm{g}}$ value indicated the complete or near complete curing systems and the temperature result were: $\mathbf{1}$ $\left(\mathrm{BHP}, 85^{\circ} \mathrm{C}\right), 2\left(60^{\circ} \mathrm{C}\right), 3\left(58^{\circ} \mathrm{C}\right), 4\left(82^{\circ} \mathrm{C}\right), 5\left(68^{\circ} \mathrm{C}\right), \mathbf{6}$ $\left(68^{\circ} \mathrm{C}\right)$, and $7\left(52^{\circ} \mathrm{C}\right)$. 3-Aminopyrazine-2-carboxylic acid 4 containing an amino group, which could be participated the polymerization, increased the crosslinking density of the polymer $\left(82^{\circ} \mathrm{C}, 4\right)$. As a result, the $T_{\mathrm{g}}$ value of compound 4 was similar to $N$-benzylpyrazinium hexafluoroantimonate $\left(85^{\circ} \mathrm{C}, \mathbf{1}, \mathrm{BHP}\right) .{ }^{43}$

The conversions of the DGEBA by catalysts 2-7 (calculated from TGA) were plotted against the curing temperature as shown in Figure 3. Except for the mild basic or basic amphiphatic piperazine catalysts 6 and 7, the conversions of all catalysts rapidly rose at specific and narrow temperature ranges (see Figure 3). For amphiphatic catalysts 6 and 7, the 
conversion rapidly increased at $>144{ }^{\circ} \mathrm{C}$, and decreased gradually at $>194{ }^{\circ} \mathrm{C}$ or $>206^{\circ} \mathrm{C}$, respectively. In the cases of DGEBA with the acidic amphiphatic pyrazine and pyridine (compounds 2-5), the conversion rapidly increased at 100$150{ }^{\circ} \mathrm{C}$ and fully curing took place at $110-160^{\circ} \mathrm{C}$ (see Figure 3 ). We thus concluded that the best molding temperature rang was $100-150{ }^{\circ} \mathrm{C}$ by using the amphiphatic catalysts 2-7.

\section{The Water-Absorption Properties}

For the study the water-absorption of the polymers, DGEBA resin and amphiphatic catalyst 3 or $7(10 \mathrm{wt} \%)$ were mixed and cured at $150{ }^{\circ} \mathrm{C}$ for $7-8 \mathrm{~h}$. The polymers were chopped in specimens of $3 \times 7 \times 50 \mathrm{~mm}$ size and exposed to humid environments $\left(72 \mathrm{~h}\right.$ at $85^{\circ} \mathrm{C} / 85 \% \mathrm{R}$.H.). The resulting moisture absorptions were obtained from weight difference and found to be lower than $1 \%$. When the specimens in same size were cooked in the boiling water for $48 \mathrm{~h}$, the average waterabsorptions were also lower than $0.6 \mathrm{wt} \%$.

\section{CONCLUSIONS}

In this work, we successfully developed a series of amphiphatic piperazine, pyrazine, and pyridine compounds with a structural feature containing the acidic carboxylic acid as thermal latent catalysts for the polymerization of diglycidyl ether of bisphenol A (DGEBA). Due to the intramolecular or intermolecular acid-base neutralization, the reactivity of piperazine, pyrazine, and pyridine moieties was reduced in the curing epoxy resins to provide the good latent properties. Based on the studies of the viscosity and $E_{\mathrm{a}}$ measurement, the activity order of the thermally latent catalytic systems was estimated to be piperazine-2-carboxylic acid (6) $>3$-aminopyrazine-2-carboxylic acid (4) $>3$-piperazin-1-yl-propionic acid $(7)>2$ pyrazinecarboxylic acid (2) $>$ picolinic acid (5) $>2,3-$ pyrazinedicarboxylic acid (3).

From the conversions results, catalysts $\mathbf{2}-\mathbf{5}$ rapidly rose at specific and narrow temperature ranges to initiate the polymerization in the molding temperature $\left(100-175^{\circ} \mathrm{C}\right)$. Concerning the glass transition temperature $\left(T_{\mathrm{g}}\right)$, the use of amphiphatic pyrazine, pyridine, and piperazine catalysts 2-5 indicated that complete or near complete curing systems obtained in the range of about $52-82{ }^{\circ} \mathrm{C}$. In the model system, the $T_{\mathrm{g}}$ values of the polymers formed by use of amphiphatic catalysts 2-7 were about $52-82{ }^{\circ} \mathrm{C}$ and the use of 3-aminopyrazine-2-carboxylic acid (4) was similar to that of $N$-benzylpyrazinium hexafluoroantimonate $\left(85^{\circ} \mathrm{C}, \mathbf{1}, \mathrm{BHP}\right)$. Due to most of the cationic latent catalysts (e.g., BHP, 1) would be released the acidic by-product including $\mathrm{HBF}_{4}, \mathrm{HPF}_{6}, \mathrm{HAsF}_{6}$ and $\mathrm{HSbF}_{6}$ to damage the electronic products, the newly developed amphiphatic catalysts might provide an alternative pathway in the manufacturing of DGEBA. Moreover, compounds 2-7 are quite or moderate stable at room temperature. The prolongation the pot-life of DGEBA resin could thus be achieved by use of these amphiphatic catalysts to enhance the storage stability and good handling of biphenyl type epoxy polymers.
Acknowledgment. We are grateful to the National Science Council of Republic of China for financial support (NSC962221-E-039-007-). We also appreciate Prof. Mou-Yung Yeh for his illuminating discussion and helpful assistance in preparing this manuscript.

Electronic Supporting Information Available: EXPERIMENTAL and Figures 1-9. These materials are available via. the Internet at http://www.spsj.or.jp/c5/pj/pj.htm

Received: March 11, 2009

Accepted: April 27, 2009

Published: June 17, 2009

\section{REFERENCES}

1. K. El Gersifi, G. Durand, and G. Tersac, Polym. Degrad. Stab., 91, 690 (2006).

2. J.-P. Yang, Z.-K. Chen, G. Yang, S.-Y. Fu, and L. Ye, Polymer, 49, 3168 (2008).

3. Q. P. Guo, A. Habrard, Y. Park, P. J. Halley, and G. P. Simon, J. Polym. Sci., Part B: Polym. Phys., 44, 889 (2006).

4. D. Ratna, R. Varley, and G. P. Simon, J. Appl. Polym. Sci., 89, 2339 (2003).

5. S. He, K. Shi, J. Bai, Z. Zhang, L. Li, Z. Du, and B. Zhang, Polymer, 42, 9641 (2001).

6. C. A. May, in "Epoxy Resins: Chemistry and Technology," 2nd ed., Marcel Dekker, New York, 1988.

7. S.-J. Park, J.-G. Kang, and S.-H. Kwon, J. Polym. Sci., Part B: Polym. Phys., 42, 3841 (2004).

8. A. Omrani, L. C. Simon, A. A. Rostami, and M. Ghaemy, Eur. Polym. J., 44, 769 (2008).

9. F. X. Perrin, T. M. H. Nguyen, and J. L. Vernet, Eur. Polym. J., 43, 5107 (2007).

10. F. F. Wong, K.-L. Chen, C. M. Lin, and M.-Y. Yeh, J. Appl. Polym. Sci., 104, 3292 (2007).

11. N. Galego and F. González, Polym. Int., 40, 213 (1996).

12. S.-J. Park, F.-L. Jin, J.-R. Lee, and J.-S. Shin, Eur. Polym. J., 41, 231 (2005).

13. S.-J. Park, M.-K. Seo, and J.-R. Lee, J. Polym. Sci., Part B: Polym. Phys., 42, 2419 (2004).

14. J. K. Lee, Y. Choi, J.-R. Lee, and J. Park, Macromol. Res., 10, 34 (2002).

15. Y. C. Kim, S.-J. Park, and J.-R. Lee, Polym. J., 29, 759 (1997).

16. S. Nakano and T. Endo, J. Polym. Sci., Part A: Polym. Chem., 34, 475 (1996).

17. Y. YaĞci and A. Önen, J. Polym. Sci., Part A: Polym. Chem., 34, 3621 (1996).

18. S.-B. Lee, T. Takata, and T. Endo, Macromolecules, 23, 431 (1990).

19. H. Uno, T. Takata, and T. Endo, Macromolecules, 22, 2502 (1989).

20. J. A. Mcgowen and L. J. Mathias, Polym. Compos., 18, 348 (1997).

21. B. X. Fu, M. Namani, and A. Lee, Polymer, 44, 7739 (2003).

22. M. Ito, H. Hata, and K. Kamagata, J. Appl. Polym. Sci., 33, 1843 (1987).

23. R. T. Shuman, P. L. Ornstein, J. W. Paschal, and P. D. Gesellchen, J. Org. Chem., 55, 738 (1990).

24. J. K. Bashkin, Curr. Opin. Chem. Biol., 3, 752 (1999).

25. M. Harfenist, J. Am. Chem. Soc., 76, 4991 (1954).

26. K. Rorig, J. D. Johnston, R. W. Hamilton, and T. J. Telinski, Org. Synth., 4, 576 (1963).

27. O. Hromatka, R. Klink, and F. Sauter, Monatsh. Chem., 93, 1294 (1962).

28. Y.-C. Chen and W.-Y. Chiu, Polymer, 42, 5439 (2001). 
29. J. M. Barton, G. J. Buist, I. Hamerton, B. J. Howlin, J. R. Jones, and S. Liu, J. Mater. Chem., 4, 379 (1994).

30. T. J. Dearlove, J. Appl. Polym. Sci., 14, 1615 (1970).

31. J. Berger and F. Lohse, J. Appl. Polym. Sci., 30, 531 (1985).

32. S. K. Ooi, W. D. Cook, G. P. Simon, and C. H. Such, Polymer, 41, 3639 (2000).

33. M. S. Heise and G. C. Martin, J. Appl. Polym. Sci., 39, 721 (1990).

34. D. R. Lide, in "CRC Handbook of Chemistry and Physics," 84th ed., 2003, p 8.

35. S. Wang and C. P. Wong, "Advanced Packaging Materials," 5th National Symposium, Institute of Electronics Enginee, 1999, p 317.

36. S.-J. Park, M.-K. Seo, J.-R. Lee, and D.-R. Lee, J. Polym. Sci., Part
A: Polym. Chem., 39, 187 (2001).

37. F. Ricciardi, W. A. Romanchick, and M. M. Joullié, J. Polym. Sci., Polym. Lett. Ed., 21, 633 (1983).

38. S.-J. Park and G.-Y. Heo, Macromol. Chem. Phys., 206, 1134 (2005).

39. S.-J. Park, T.-J. Kim, and J.-R. Lee, J. Polym. Sci., Part B: Polym. Chem., 38, 2114 (2000).

40. H. Cai, P. Li, G. Sui, Y. Yu, G. Li, X. Yang, and S. Ryu, Thermochim. Acta, 473, 101 (2008).

41. L. Núñez, M. R. Núñez, M. Villanueva, A. Castro, and B. Rial, J. Appl. Polym. Sci., 85, 366 (2002).

42. N. Galego and F. González, Polym. Int., 40, 213 (1996).

43. M. S. Heise and G. C. Martin, Macromolecules, 22, 99 (1989). 